\title{
Dependence of Magnetization Dynamics and Magneto-IImpedance Effect in FeSiB Amorphous Wire on Annealing Conditions
}

\author{
Y.Takemura, H.Tokuda, K.Komatsu, S.Masuda ${ }^{\text {a) }}$, T.Yamada, K.Kakuno and K.Saito ${ }^{\text {b) }}$ \\ Yokohama National University, 156 Tokiwadai, Hodogaya, Yokohama 240, Japan \\ a) Jeco Co.,1-4-1 Fujimicho, Gyoda, Saitama 361, Japan \\ ${ }^{b}$ Teikyo University of Science and Technology, 2525 Yatsusawa, Uenohara, Yamanashi 409-01, Japan
}

\begin{abstract}
Dependence of magnetization dynamics and magneto-impedance effect in positively magnetostrictive $\mathrm{Fe}_{775} \mathrm{Si}_{75} \mathrm{~B}_{15}$ amorphous wires on annealing conditions was studied. The observed MI ratio of the annealed samples was as much as $36 \%$ and the optimum annealing conditions were suggested. The locus of magnetization vector of the annealed wire indicated that the circumferential magnetization was easily proceeded in the annealed wire. It was also suggested that the effect of oxidation should be considered for the samples annealed in air.
\end{abstract}

\section{INTRODUCTION}

The magneto-impedance (MI) effect in amorphous magnetic wires $[1,2]$ has recently attracted much attention. It is a large impedance change with a small external magnetic field, which is expected to be utilized in a new kind of sensitive magnetic sensor. It has been reported that $\mathrm{Fe}_{4.3} \mathrm{Co}_{68.2} \mathrm{Si}_{12.5} \mathrm{~B}_{15}$ amorphous wire with slightly negative magnetostriction exhibits a large MI effect and that the effect is correlated closely to the domain structures and magnetization dynamics in the wire[1,2]. $\mathrm{Fe}_{4.3} \mathrm{Co}_{68.2} \mathrm{Si}_{12.5} \mathrm{~B}_{15}$ amorphous wire has a circumferencial magnetic domain structure. The permeability of this circumferencial component is high and sensitive to the axial magnetic field, which results in a large impedance change with applied field

Although $\mathrm{Fe}_{77.5} \mathrm{Si}_{7.5} \mathrm{~B}_{15}$ amorphous wire with a positive magnetostriction has a radial easy axis structure, it has been also reported that annealing induces a circumferencial domain structure and that the annealed wire exhibits a larger impedance change than the as-quenched wire[3].

In this paper, magnetization dynamics and $\mathrm{MI}$ effect were investigated using amorphous $\mathrm{Fe}_{77.5} \mathrm{Si}_{7.5} \mathrm{~B}_{15}$ wires annealed under various conditions :

(1) annealing temperature and annealing time.

(2) annealing in a furnace or by Joule heat from a current through the wire.

(3) annealing in air or in vacuum.

\section{EXPERIMENTS}

The sample was positively magnetostrictive $\mathrm{Fe}_{77.5} \mathrm{Si}_{7.5} \mathrm{~B}_{15}$ amorphous wire. The as-cast wire with a diameter of $200 \mu \mathrm{m}$

Manuscript reccived March 7, 1996

Y.Takemura, e-mail takemura@dnj.ynu.ac.jp, fax +81-45-338-1157 which was kindly supplied by Unitika Co., Japan was used. The furnace annealing of the wire was carried out at 200$400^{\circ} \mathrm{C}$ for $10-60$ min under no tension either in vacuum or in air. No external magnetic field was applied to the samples during the annealing. Current annealing was also carried out using a current through the sample wire of $0.8 \mathrm{~A}$ for 10 $60 \mathrm{~min}$. The DC resistance of wires did not change with annealing, which suggested that no significant crystallization occurred.

The impedance measurement was performed with wires of $20 \mathrm{~mm}$ length under tension of $0.092 \mathrm{~kg} / \mathrm{mm}^{2}$. The constant tension was significant, because the impedance of positively magnetostrictive $\mathrm{Fe}_{77.5} \mathrm{Si}_{7.5} \mathrm{~B}_{15}$ amorphous wire sensitively changed with their tension. The electrical measurement of wires without any tension was quite difficult comparing to that applying the constant tension. The MI ratio was defined as in other reports by $\left(E_{\mathrm{w} 0}-E_{\mathrm{w}}\right) / E_{\mathrm{w} 0}$, where $E_{\mathrm{w} 0}$ and $E_{\mathrm{w}}$ are peak-to-peak voltages across the wire measured with $A C$ current of $15 \mathrm{~mA}_{\mathrm{p}-\mathrm{p}}$ under the external DC magnetic field, $H_{\mathrm{ex}}$ of 0 and $61 \mathrm{Oe}$, respectively. $H_{\mathrm{ex}}$ was applied along the wire axis. The sinusoidal voltage was observed with sinusoidal AC current both for $E_{\mathrm{w} 0}$ and $E_{\mathrm{w}}$. As discussed in the next section, MI ratio of both as-cast and annealed $\mathrm{Fe}_{77.5} \mathrm{Si}_{7.5} \mathrm{~B}_{15}$ wires investigated in this study did not saturate with the field up to $60 \mathrm{Oe}$, which was attributed to the radial domain structure of the wire.

Auger electron spectroscopy (AES) was performed in order to examine the effect of oxidation of the sample wires. In this measurement, $\mathrm{Fe}_{77.5} \mathrm{Si}_{7.5} \mathrm{~B}_{15}$ amorphous ribbons (2mm width and $30 \mu \mathrm{m}$ thickness) were annealed by the same method as the wires in a furnace. This was because the shape and size of the wire was not suitable for the AES measurement, especially for the depth profile analysis.

\section{RESULTS AND DISCUSSION}

Fig. 1 shows the observed MI ratio indicated as a function of $\mathrm{AC}$ current frequency for the samples furnaceannealed for $10 \mathrm{~min}$ in air. The as-cast and $200^{\circ} \mathrm{C}$-annealed wires exhibit maximum (peak) values of the MI ratio of around $10 \%$ at the $\mathrm{AC}$ current frequency of $500 \mathrm{kHz}$. By increasing the annealing temperature, the $\mathrm{MI}$ ratio increases up to $32 \%$ (annealed at $400^{\circ} \mathrm{C}$ ). A similar measurement was carried out for samples annealed in vacuum. There were no significant differences between the samples 


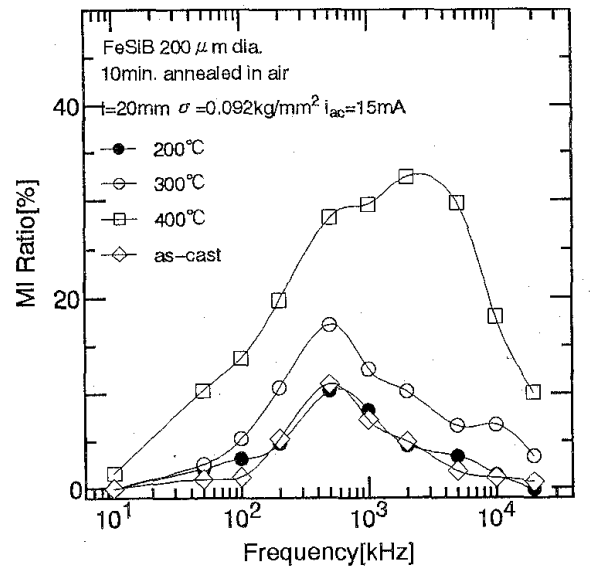

Fig.1 MI ratio of $\mathrm{Fe}_{775} \mathrm{Si}_{75} \mathrm{~B}_{15}$ wires measured as a function of current frequency. Samples are as-cast and annealed at $200,300,400^{\circ} \mathrm{C}$ for $10 \mathrm{~min}$ in air.

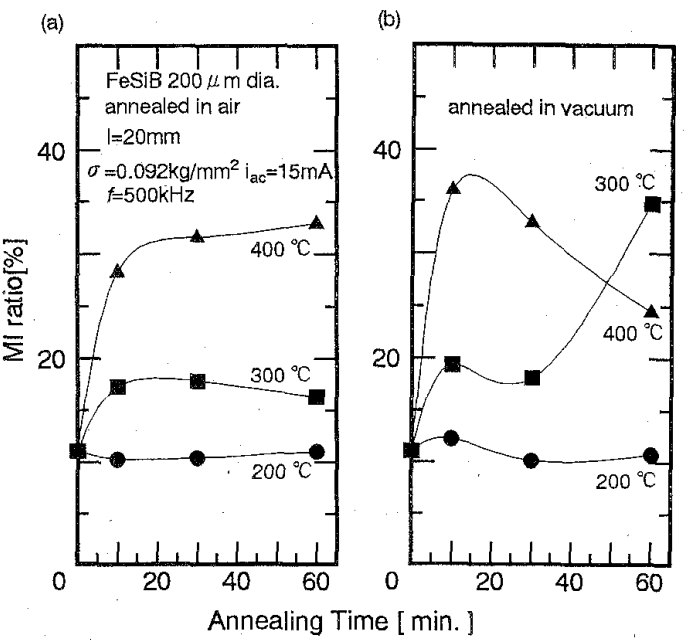

Fig.2 MI ratio of $\mathrm{Fe}_{77.5} \mathrm{Si}_{7.5} \mathrm{~B}_{15}$ wires indicated as a function of annealing time. Annealing was carried out under various temperature in air(a) and vacuum(b), respectively. MI ratio describes its peak value measured against current frequency.

annealed for $10 \mathrm{~min}$ in air and in vacuum. Fig. 2(a) shows the peak values of the MI ratio for the samples annealed in air. The MI ratio does not increase much for the samples annealed at $200^{\circ} \mathrm{C}$ and $300^{\circ} \mathrm{C}$, but annealing at $400^{\circ} \mathrm{C}$ is effective to increase the MI ratio. Fig. 2(b) shows similar plots of the MI ratio for samples annealed in vacuum. The annealing at $300^{\circ} \mathrm{C}$ for $60 \mathrm{~min}$ was effective to increase the MI ratio, but the annealing at $400^{\circ} \mathrm{C}$ for $60 \mathrm{~min}$ caused the decrease in MI ratio. This over-annealing might change a surface magnetic domain structure which resulted in reduction of MI ratio. From these results, it is found that the annealed $\mathrm{Fe}_{775} \mathrm{Si}_{75} \mathrm{~B}_{15}$ amorphous wires exhibit a large MI effect, as much as $36 \%$, and the optimum annealing conditions are suggested for both in air and vacuum annealing. The difference in the MI characteristics between the samples annealed in air and vacuum is presumably due to an heat-radiation in air.

Fig. 3 shows the MI ratio of the samples annealed by

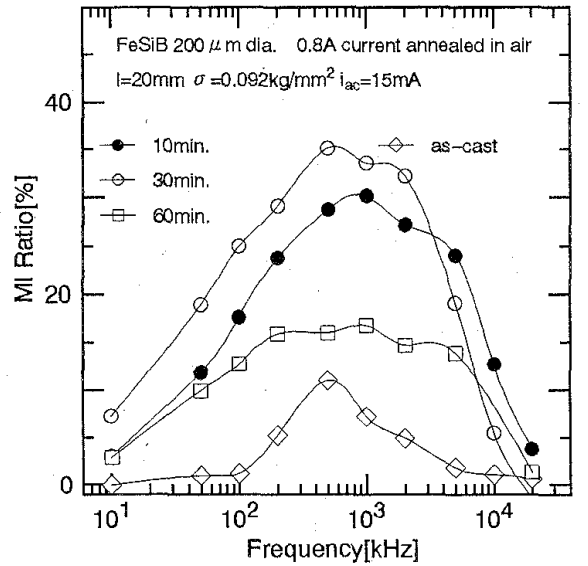

Fig.3 MI ratio of $\mathrm{Fe}_{77.5} \mathrm{Si}_{7.5} \mathrm{~B}_{15}$ wires measured as a function of current frequency. Samples are as-cast and annealed by current in air.

current in air. In current annealing at $0.8 \mathrm{~A}$, an annealing time of 20 or $30 \mathrm{~min}$ is enough to obtain the MI ratio of $30 \%$. The curves are similar to those of the samples annealed in the furnace and no effect of circumferencial magnetic field generated by the current is seen in the MI characteristics. As for the current-annealing in vacuum, no increase of the impedance is observed from samples annealed up to $60 \mathrm{~min}$.

Although the impedance change of $\mathrm{Fe}_{4.3} \mathrm{Co}_{68.2} \mathrm{Si}_{12.5} \mathrm{~B}_{15}$ saturates with small $H_{\text {ex }}$ around $5 \mathrm{Oe}[2]$, that of $\mathrm{Fe}_{77.5} \mathrm{Si}_{7.5} \mathrm{~B}_{15}$ does not saturate with more than 60 Oe both for as-cast and annealed. The difference is attributed to the domain structures. The locus of magnetization vector in magnetization dynamics from $\mathrm{Fe}_{4.3} \mathrm{Co}_{68.2} \mathrm{Si}_{12.5} \mathrm{~B}_{15}$ amorphous wire is measured as shown in Fig. 4. Details of the measurement and sample have been reported in Ref. 4 . The locus changes with increasing $H_{\mathrm{ex}}$, which can be explained by assuming the circumferential domain structure in the wire. Fig.5 shows the locus observed from $\mathrm{Fe}_{77.5} \mathrm{Si}_{7.5} \mathrm{~B}_{15}$ wires under tension of $0.092 \mathrm{~kg} / \mathrm{mm}^{2}$. Units used in Fig.4 and Fig.5 are different for both longitudinal and circumferencial components. The magnetization easily takes place toward both longitudinal(axial) and circumferential direction in annealed wire $\left(400^{\circ} \mathrm{C}, 60 \mathrm{~min}\right.$ in vacuum), which is completely different from that in as-cast wire. The asymmetric loop of magnetization in annealed wire is affected by residual magnetization. This result agrees with the suggestion that the annealing induces circumferential domain structure in $\mathrm{Fe}_{77.5} \mathrm{Si}_{7.5} \mathrm{~B}_{15}$ wire[3]. In that report, the induced circumferencial domain structures of the annealed samples are explained by surface crystallization. It has been also suggested that the increase of the MI ratio observed in annealed $\mathrm{FeCuNbSiB}$ amorphous wires is attributed to the precipitation of homogeneous $\mathrm{FeSi}$ nanocrystalline structure and partial crystallization of the wires[5].

Fig. 6(a) and 6(b) show the depth profiles of as-cast and annealed $\left(400^{\circ} \mathrm{C}\right.$ for $180 \mathrm{~min}$ in air) $\mathrm{Fe}_{77.5} \mathrm{Si}_{7.5} \mathrm{~B}_{15}$ amorphous ribbons measured by AES. The depth in the profiles is 


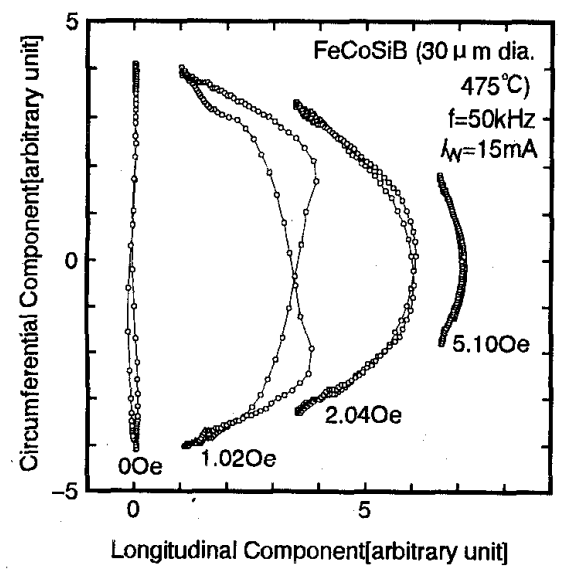

Fig.4 Locus of magnetization vector observed from $\mathrm{Fe}_{4.3} \mathrm{Co}_{68.2} \mathrm{Si}_{12.5} \mathrm{~B}_{15}$ wire. External magnetic field, $H_{\mathrm{ex}}$ is varied with $0,1.02,2.04$ and $5.1 \mathrm{Oe}$.

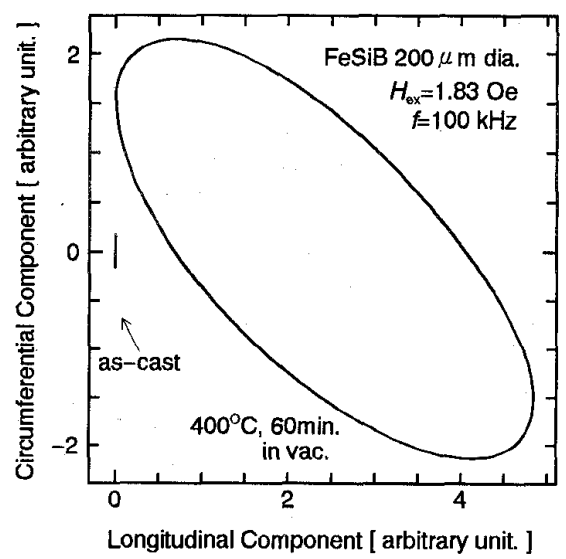

Fig.5 Locus of magnetization vector observed from $\mathrm{Fe}_{77.5} \mathrm{Si}_{7.5} \mathrm{~B}_{15}$ amorphous wires of as-cast and annealed at $400^{\circ} \mathrm{C}$ for $60 \mathrm{~min}$ in vacuum.

calculated from the sputtering rate of about $10 \mathrm{~nm} / \mathrm{min}$. The signal intensities for each element are not normalized. The detected signal of oxygen from the surface to $30 \mathrm{~nm}$ depth in Fig. 6(a) is not related to the oxidation of the sample. It results from the production process and is found in all amorphous ribbons. As indicated in Fig. 6(b), the annealed sample exhibits oxygen up to $100 \mathrm{~nm}$ depth which differs from that in Fig. 6(a) and confirms surface oxidation for this annealed sample. Therefore it is suggested that the crystallization process associated with oxidation should be considered for samples annealed in air.

\section{CONCLUSION}

Dependence of magnetization dynamics and magnetoimpedance effect in positively magnetostrictive $\mathrm{Fe}_{775} \mathrm{Si}_{75} \mathrm{~B}_{15}$ amorphous wires on annealing conditions was studied. The observed MI ratio was as much as $36 \%$ for annealed samples, and the optimum annealing conditions were suggested for
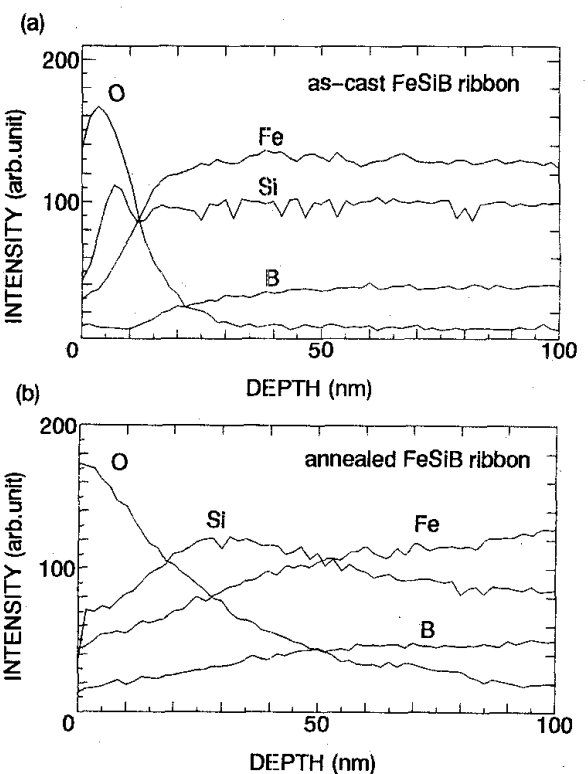

Fig.6 Depth profiles measured by Auger electron spectroscopy (AES) from the as-cast(a) and the annealed(b) $\mathrm{Fe}_{775} \mathrm{Si}_{75} \mathrm{~B}$ amorphous ribbons, respectively. The annealing was carried out at $400^{\circ} \mathrm{C}$ for $180 \mathrm{~min}$.

both air and vacuum annealing. Although the significant differences were not obtained between the samples annealed in air and vacuum from MI ratio vs. frequency plot, the crystallization process associated with or enhanced by the oxidation should be considered for the samples annealed in air. The observed magnetization dynamics indicated that circumferential magnetization was easily produced in the annealed wire, which was attributed to the increase of the impedance change. This result agreed with the suggestion that the annealing induces circumferential domain structure in $\mathrm{Fe}_{77.5} \mathrm{Si}_{75} \mathrm{~B}_{15}$ wire.

\section{ACKNOWLEDGMENT}

The authors acknowledge Mr.Ogasawara at Unitika Co., Japan for providing FeSiB amorphous wires.

\section{REFERENCES}

[1] K.Mohri, K.Bushida, M.Noda, H.Yoshida, L.V.Panina and T.Uchiyama, "Magneto-impedance element," IEEE Trans. Mag., vol.31, pp.2455-2460, 1995

[2] L.V.Panina, K.Mohri, T.Uchiyama and M.Noda, "Giant magnetoimpedance in Co-rich amorphous wires and films," IEEE Trans. Mag., vol.31, pp.1249-1260, 1995

[3] D.Atkinson, R.S.Beach, P.T.Squire, C.L.Platt and S.N.Hogsdon, "Magneto-impedance and $\triangle \mathrm{E}$ measurements of iron- and cobalt-based amorphous wires," IEEE Trans. Mag., vol.31, pp.3892-3894, 1995

[4] K.Komatsu, S.Masuda, Y.Takemura, T.Yamada and K.Kakuno, "Dynamic magnetization process in $\mathrm{FeCoSiB}$ amorphous wire under trigonal magnetic field", Dig. INTERMAG 96, HS-8, Seattle, 1996

[5] M.Knobel, M.L.Sanchez, P.Marin, C.Gomez-Polo, M.Vazquez and A.Hemado, "Influence of Nanocrystallization of the Magneto-Impedance Effect in FeCuNbSiB Amorphous Wires," IEEE Trans. Mag., vol.31, pp.4009-4011, 1995 